\title{
A Study of the Influence of Tourists' Destination Image and Perceived Service Quality on Their Behavioral Intention
}

\author{
Shihui Pan ${ }^{1 *}$, Chih-Wei Chang', Ziyi Zhu' ${ }^{1}$ \\ ${ }^{1}$ School of News and Commmunication, Huanggang Normal University, Huanggang, China \\ ${ }^{2}$ School of Humanities, Shanghai Normal University, Shanghai, China \\ Email: *panshihui@hgnu.edu.cn
}

How to cite this paper: Pan, S.H., Chang, C.-W. and Zhu, Z.Y. (2021) A Study of the Influence of Tourists' Destination Image and Perceived Service Quality on Their Behavioral Intention. Open Journal of Applied Sciences, 11, 585-595.

https://doi.org/10.4236/ojapps.2021.115042

Received: April 24, 2021

Accepted: May 25, 2021

Published: May 28, 2021

Copyright $\odot 2021$ by author(s) and Scientific Research Publishing Inc. This work is licensed under the Creative Commons Attribution International License (CC BY 4.0).

http://creativecommons.org/licenses/by/4.0/

\begin{abstract}
The purpose of this study is to understand the effect of tourists' perception of destination image and service quality on their behavioral intention. A total of 1020 valid questionnaires were collected from tourists in Lukang Town, Taiwan, by means of convenient sampling. After descriptive statistics and PLS statistical analysis, the results show that: 1) Tourists' image of Lukang town has a positive effect on their perceived service quality. In addition, it also has a positive effect on future travel behavior intention; 2) The service quality of tourists in Lukang has a positive effect on their future travel behavior intention. 3) This study also finds that service quality has a mediating effect on tourism behavior intention. Finally, based on the results of the study, suggestions for future research and tourism planning are put forward.
\end{abstract}

\section{Keywords}

Destination, Image, Service Quality, Behavioral Intention, Lukang

\section{Introduction}

In recent years, with the prosperity of tourism in Taiwan, people like to visit outdoor natural environments or villages and towns with well-preserved cultures on holidays [1]. Lukang Town, located in the central part of Taiwan, was once the economic transportation hub between the two sides of the Taiwan Strait during the Qing Dynasty. As a result, it has many unique historical, cultural, historic buildings, temples, food, and crafts. Lugang is rich in cultural history, ancient and magnificent historic buildings, delicious snacks with local characteristics, and folk festival activities with ancient flavor. Every holiday time, the 
streets and lanes are always full of people and traffic, which shows that Lugang has its unique image and attracts tourists [2]. According to Crompton's (1979) definition of image, image is the sum of people's beliefs, impressions, ideas, and feelings about certain objects, actions, and events [3]. Moreover, destination image has the function of communication, publicity, and marketing, which will help tourists to consider and decide the destination they want to choose [4]. Then, when tourists are attracted by the destination image and go to the tourism destination to engage in activities, what they are faced with is the local service quality. Previous studies on tourism have found that the image of tourists before visiting the destination is related to the service quality they feel on the spot. Moreover, the service quality will affect tourists' willingness to visit their destinations in the future, or their behavior intention [5]. Baker and Crompton (2000) considered that post tourism behavioral intention is an indicator of whether tourists return to their destination [6]. Therefore, according to the above background, the purpose of this study is as follows:

1) Analyze the effect of tourists' tourism image on tourism quality and behavior intention.

2) Analyze the effect of tourists' perception of the tourism quality of Lugang town on their behavior intention.

\section{Literature Review and Research Hypothesis}

In the field of tourism research, the concept of image is often used in the study of travel destination marketing and explains the choice of travel destination [4] [7], whether the generation of images will have a positive impact and substantial help on the tourism destination, and whether tourists will have a positive attraction to the tourism destination through the connection of images. Echtner and Ritchie (1993) proposed that the composition of tourism image can be divided into five aspects, including tourism attraction, tourism activities, tourism services, tourism visibility and tourism management [8]. Birgit (2001) divides tourism image into three dimensions, including natural landscape image, social culture image and local culture image [9]. For example, Binh (2020) studies that Vietnamese tourists always have a high and positive evaluation of Taiwan. Tourism destinations are mainly scenic areas in Taiwan, followed by Taiwan's customs and multi culture. Another factor that attracts Vietnamese tourists is the quality of service industry, people's friendliness and enthusiasm, and good social order. In the further empirical study, it is found that goal image has a positive impact on service quality [10]. In the study of Lin (2020), she found that tourists' image of the destination will affect their visiting behavior in the future, so she learned that the image of the destination has an effect on their behavior intention. Although destination image plays an important role in inspiring tourist behavior, the service quality that tourists feel when they travel to the destination is also very important [11]. Parasuraman, Zeithaml and Berry (1985) developed "service quality model", also known as "PZB model". The main concept is that consumers are the decision makers of service quality. If enterprises want to meet the 
needs of consumers, they must make up for the five gaps found in this model. The five gaps are: 1) the cognitive gap between customer expectations and managers; 2) The gap between managers and service specifications; 3) The gap between service quality specification and service communication process; 4) The gap between service delivery and external communication; 5) Customer expectation and service gap after experience. Although PZB model is widely used in consumer behavior research as the basis of service quality measurement, it has its limitations [12]. The empirical results of Fick and Ritchie (1991) show that SERVQUAL scale cannot effectively measure customers' emotional experience, because only considering the business model of service transaction, it ignores the relationship between social and psychological aspect [13]. For example, Mudner (2020) studies that Russian tourists attach a great importance to Taiwan's service quality. The highest value is tangible (tourist facilities, hotels, transportation, restaurants), reactive (tourism service staff's ability to meet tourists' needs), authentic (tourism service personnel can solve the problem of tourists' response), and the lowest value is reliability (personnel services of government tourism department and tourism industry) and empathy (Government Tourism Department and tourism industry personnel can care, care and take care of tourists) [14]. However, in the above research, there is no specific explanation for the specific impact on the destination tourism resources. For example, in Hong (2019) to study the behavior of Green Island tourists, it is found that the tourism resources of the tourist destination humanities and the quality of service will affect the willingness of the tour leaders to recommend the destination [15]. The behavior of tourists includes the choice of destination and visit, and is accompanied by the evaluation of tourism products and future behavior intention [16]. As behavioral intention is an important indicator to evaluate tourists' future revisit and recommend destinations to others, it is found that destination image and local service quality have an impact on tourists' behavioral intention [17] [18] [19]. Therefore, according to the above discussion and the purpose of this study, this study puts forward the following three hypotheses, and summarizes the relationship of the hypotheses as shown in Figure 1:

H1: Tourists' perception of Lukang image has a positive effect on the service quality of the destination.

H2: Tourists' perception of Lukang image has a positive effect on the behavioral intention.

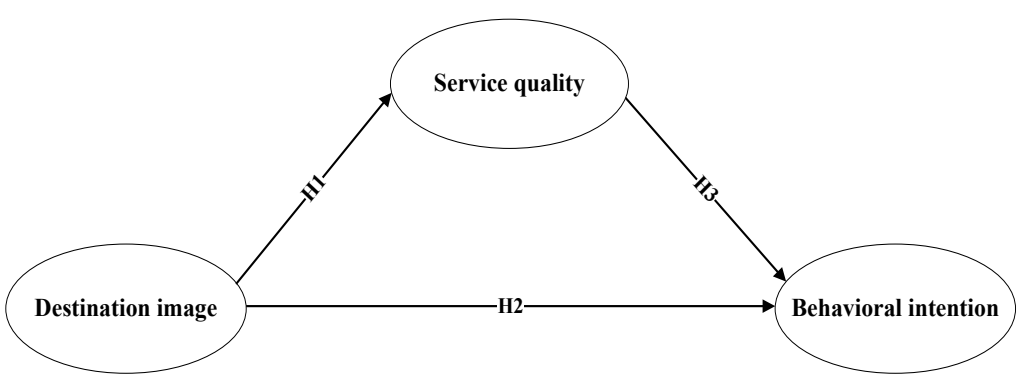

Figure 1. Hypothetical model. 
H3: The tourists' service quality feeling in the Lukang has a positive effect on behavior intention.

\section{Research Methods}

\subsection{Subject and Sampling}

This study takes the tourists to Lukang town as the subjects. From June 1 to 9, 2018, a convenient sampling method was used to investigate the tourists in the parking lots of Wenwu temple and Mazu temple in Lukang town. Before conducting the questionnaire survey, tourists were asked about their wishes and to confirm that they were coming to Lukang for tourism, and then they were asked to fill in the questionnaire, according to their willingness. In this study, a total of 1200 questionnaires were given to tourists, 1058 questionnaires were returned, 38 invalid questionnaires were deducted, and 1020 valid questionnaires were returned, with the effective rate of $85 \%$.

\subsection{Questionnaire}

This research tool is divided into five parts. The first part is "tourism destination image scale", which contains 22 questions. The main purpose is to understand tourists' impression, expectation and imagination of Lukang Town, as well as their feelings about the environment, traffic and overall evaluation of the town. This part of the scale is mainly based on Chang Liao's (2010) research scale of Lugang tourism image [20]. In her study, the scale adopts the exploratory factor analysis method, a total of five factors were analyzed. They are "diversified folk activities", "famous cultural relics", "famous snacks with special characteristics", "famous handicrafts" and "famous Mazu”, which can explain 55.69\% of tourists" interpretation of "tourism image" of Lukang town. Because part of the content of the scale developed by Chang Liao's (2010) is a little different from the current situation in Lukang, the researchers have revised the meaning of the part.

The second part is "scale of service quality in Lukang". There are 23 questions in total. The main purpose of this part is to know the tourists' quality of historical relics preservation, scenic spot service, traffic condition, scenic spot service, catering service, environmental cleaning, traffic, snacks and public facilities in Lukang town. This part of the scale is mainly based on Chang Liao's (2010) research scale of Lugang tourism service quality. In her study, the scale is an exploratory factor analysis method, which includes five factors: cultural relics, restaurants, scenic spots, environment cleaning and negative perception [20]. The explanation of tourists to the tourism image of Lugang town is $58.70 \%$. Because part of the content of the scale developed by Chang Liao's (2010) is a little different from the current situation in Lukang, the researchers have revised the meaning of the part. The third part is "behavioral intention scale", which consists of five questions. The main purpose is to understand tourists' willingness to come to Lukang town for tourism activities in the future, and their willingness to recommend relatives and friends. This part is compiled by referring to the rele- 
vant study of tourism behavior intention [17]. The questions in the above three scales were answered on a 5-point Likert scale, and they were given 1 - 5 scores respectively from "very disagree", “disagree”, "common", "agree”, "extraordinary consent".

The fourth part is personal data, including: gender, age, marital status, education level, occupation, income, residence and other seven items.

\subsection{Data Analysis}

The statistical analysis steps of this study are as follows: 1) Use the frequency distribution and percentage of descriptive statistics to explain the distribution of demographic variables. 2) Using partial least squares (PLS) statistical method to analyze the reliability and validity of tourists' perception of destination image, service quality, and behavioral intention, as well as the structural relationship between variables. 3) Composite reliability (CR) and Cronbach's $\alpha$ value were used to determine the reliability of the three scales. The test standard of CR and Cronbach's $\alpha$ value should be equal to or greater than 0.70 [21]. 4) The factor loading (FL) of each observed variable and the average variance extracted (AVE) of the potential variable must be greater than 0.50 to determine whether each potential variable has a convergent validity (Hair, Black, Babin, \& Anderson, 2010). 5) In the pattern structure relationship, the explanatory power of the model was judged by: a) whether the standardized path coefficient reached statistical significance; $b$ ) the value of $R^{2}$ [22].

\section{Result}

\subsection{Analysis of Effective Sample Characteristics}

Among 1020 valid questionnaires, 479 (47\%) were male and 541 (53\%) were female. In terms of marital status, 703 (68.9\%) were married and 317 (31.1\%) were unmarried. The number of people aged 21 to 30 years old was the highest, accounting for 424 (41.6\%), and the least was over 51 years old, accounting for 40 (3.9\%). The most educational level was college, accounting for 469 (46\%), and the least was junior high school (including below), accounting for 55 (5.4\%). In terms of occupation, the service industry accounted for the largest number of people, accounting for 294 (28.8\%), and the least was the unemployed, accounting for 16 (1.6\%). In terms of personal monthly income, 391 people (38.3\%) had an income of NT $\$ 20,000$ - 40,000 (about US $\$ 700$ - 1300), while 24 people (2.4\%) had an income of more than NT \$80,001 (about US \$2600).

\subsection{Reliability and Validity Analysis}

\subsubsection{Destination Image Scale}

The results from Table 1 show that the factor loading of each observation variable is more than 0.50, the CR and Cronbach's $\alpha$ are higher than 0.70 , and the AVE of potential variables is higher than 0.50 , which shows that the scale has good convergent validity. 
Table 1. Confirmatory factor analysis results of destination image scale.

\begin{tabular}{|c|c|c|c|c|}
\hline Factors/Items & FL & $\mathrm{CR}$ & Cronbach's $\alpha$ & AVE \\
\hline \multicolumn{5}{|l|}{ Diversified folk activities } \\
\hline 9. Many performances in the incense troupe and the array head. & 0.76 & 0.86 & 0.82 & 0.59 \\
\hline 8. Many folk festivals. & 0.76 & & & \\
\hline 10. Rich historical buildings (such as temples and ancient houses). & 0.75 & & & \\
\hline 7. Religious customs are strong. & 0.73 & & & \\
\hline 11. It has rich folk cultural relics. & 0.69 & & & \\
\hline 6. There are many pilgrims praying and praying. & 0.66 & & & \\
\hline \multicolumn{5}{|l|}{ Famous cultural relics } \\
\hline 2. Wooden crafts are well known in Taiwan. & 0.76 & 0.83 & 0.82 & 0.52 \\
\hline 5. It has a simple traditional town scenery. & 0.70 & & & \\
\hline 1. There is a well-known national first-class historic site-Longshan temple. & 0.63 & & & \\
\hline 3. The well-known old street settlement remains intact. & 0.69 & & & \\
\hline 4. The place is well-known in Taiwan. & 0.71 & & & \\
\hline \multicolumn{5}{|l|}{ Special famous snacks } \\
\hline 18. Local snacks make people feel nostalgic. & 0.85 & & & \\
\hline 19. Lugang steamed stuffed bun is delicious and well-known in Taiwan. & 0.79 & 0.85 & 0.74 & 0.65 \\
\hline 17. Traditional tea and snacks have local characteristics. & 0.79 & & & \\
\hline \multicolumn{5}{|l|}{ The handicraft is well known } \\
\hline 15. Incense making is well known in Taiwan. & 0.75 & & & \\
\hline 16. The tin art of hand carving is well known in Taiwan. & 0.78 & 0.86 & 0.79 & 0.64 \\
\hline 21. Traditional carpentry is well known. & 0.73 & & & \\
\hline 20. Folk arts are well known in Taiwan. & 0.76 & & & \\
\hline 22. The traditional folk arts are well preserved. & 0.69 & & & \\
\hline \multicolumn{5}{|l|}{ Mazu is famous } \\
\hline 13. It has the famous Mazu temple. & 0.82 & 0.81 & 0.70 & 0.62 \\
\hline 12. Local Mazu is very effective. & 0.77 & & & \\
\hline 14. There are a lot of pilgrims to Mazu temple in Lugang. & 0.71 & & & \\
\hline
\end{tabular}

\subsubsection{Service Scale}

The results from Table 2 show that the factor loading of each observation variable is more than 0.50, the CR and Cronbach's $\alpha$ are higher than 0.70 , and the AVE of potential variables is higher than 0.50 , which shows that the scale has good convergent validity.

\subsubsection{Behavioral Intention Scale}

The results from Table 3 show that the factor loading of each observation variable is more than 0.50, the CR and Cronbach's $\alpha$ are higher than 0.70 , and the AVE of potential variable is higher than 0.50 , which shows that the scale has good convergent validity. 
Table 2. Confirmatory factor analysis results of service scale.

\begin{tabular}{|c|c|c|c|c|}
\hline Factors/Items & FL & $\mathrm{CR}$ & Cronbach's $a$ & AVE \\
\hline \multicolumn{5}{|l|}{ Catering services } \\
\hline 2. The restaurant is very convenient. & 0.82 & 0.88 & 0.82 & 0.64 \\
\hline 1. The service attitude of the store is good. & 0.79 & & & \\
\hline 3. The food and beverage hygiene is good. & 0.84 & & & \\
\hline 4. The price of food and beverage products is reasonable. & 0.76 & & & \\
\hline \multicolumn{5}{|l|}{ Clean environment } \\
\hline 15. The environment of the scenic spot is clean. & 0.87 & 0.88 & 0.86 & 0.64 \\
\hline 14. Public toilets are clean and comfortable. & 0.82 & & & \\
\hline 16. The streets are clean and tidy. & 0.82 & & & \\
\hline 13. Parking facilities are adequate and good. & 0.69 & & & \\
\hline \multicolumn{5}{|l|}{ Scenic spot service } \\
\hline 22. The service quality of scenic spot personnel is good. & 0.74 & 0.84 & 0.71 & 0.52 \\
\hline 23. The safety measures of tourist attractions are good. & 0.81 & & & \\
\hline 21. There are many scenic spots. & 0.71 & & & \\
\hline 20. The transportation is convenient. & 0.75 & & & \\
\hline 19. The signs of the scenic spots are clear. & 0.56 & & & \\
\hline \multicolumn{5}{|l|}{ Snacks and local specialties } \\
\hline 9. Snacks are hygienic and delicious. & 0.71 & 0.85 & 0.77 & 0.59 \\
\hline 10. The price of snacks is reasonable. & 0.81 & & & \\
\hline 11. The price of souvenirs is reasonable. & 0.79 & & & \\
\hline 12. The price of famous products is reasonable. & 0.76 & & & \\
\hline \multicolumn{5}{|l|}{ Residents' friendliness } \\
\hline 6. The residents have a cordial attitude. & 0.78 & 0.86 & 0.79 & 0.61 \\
\hline 7. Public order is good. & 0.0 .83 & & & \\
\hline 8. Residents will kindly guide tourists. & 0.79 & & & \\
\hline 5. Residents will not be hostile to tourists. & 0.0 .72 & & & \\
\hline
\end{tabular}

Table 3. Confirmatory factor analysis results of behavioral intention scale.

\begin{tabular}{|c|c|c|c|c|}
\hline Items & FL & CR & Cror & AVE \\
\hline 1. In the future, I will want to come back to Lukang to engage in tourism activities. & 0.76 & 0.86 & 0.79 & 0.55 \\
\hline 2. I would be happy to suggest and recommend friends and relatives to visit Lukang. & 0.79 & & & \\
\hline 3. I will be glad to advise the relevant competent authorities in case of any improvement in Lugang. & 0.65 & & & \\
\hline 4. In Lukang, I will be happy to make suggestions to the relevant authorities. & 0.74 & & & \\
\hline 5. As long as there are festival activities in Lukang, I will be happy to engage in tourism activities again. & 0.77 & & & \\
\hline
\end{tabular}

\subsubsection{Analysis of Discriminant Validity}

The results in Table 4 show that the square root of AVE of all potential variables is between 0.74 and 0.79 , and the AVE of each potential variable is greater than all the correlation coefficients in the same column and column, indicating that the measurement models of each scale have good discriminant validity. 
Table 4. Discriminant validity analysis of summary results.

\begin{tabular}{cccc}
\hline Variables & Destination image & Service quality & Behavioral intention \\
\hline Destination image & $\mathbf{0 . 7 7}$ & 0.47 & 0.47 \\
Service quality & 0.47 & $\mathbf{0 . 7 9}$ & 0.47 \\
Behavioral intention & 0.47 & 0.47 & $\mathbf{0 . 7 4}$ \\
\hline
\end{tabular}

Notes: Square roots of average variances extracted (AVEs) shown on diagonal.

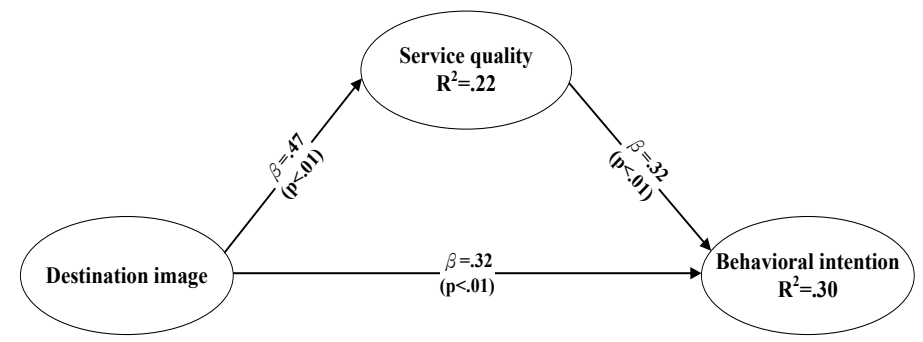

Figure 2. Structural model.

\subsection{Structural Model Analysis}

The test of structural model is used in this study, and the results of structural equation model are shown in Figure 2. In the figure, the path coefficient is the standardized regression coefficient ( $\beta$ value). In terms of the relationship between the variables, the standardized coefficient among the variables shows that "destination image" has a positive effect on "service quality" $(\beta=0.47, \mathrm{P}<0.01)$. In addition, destination image had a positive effect on behavioral intention ( $\beta=$ $0.32, \mathrm{P}<0.01)$. Then, "service quality" had a positive effect on "behavior intention" $(\beta=0.32, \mathrm{P}<0.01)$.

From the above structural relationship, because destination image has a positive effect on service quality and behavior intention, we can find that service quality plays a partial intermediary role in the structural model. Furthermore, from the results of the relationship among the variables in Figure 2, we can find that the explanatory power of destination image on service quality is $22 \%$, and that of service quality on behavior intention is $30 \%$.

\section{Discussion, Conclusion and Suggestion}

\subsection{Discussion}

The results show that tourists' image of Lukang has a positive impact on their current tour ism quality, so hypothesis 1 is supported. The results of the above analysis support the relevant tourism research [17] that tourists will compare their previous destination images after arriving at the local tourism. When the local service quality matches the previous image, they will feel better about the local service quality. For example, Chen (2019) studied the tourist image of Guanziling hot spring area in Tainan, and found that positive tourism image had a significant positive impact on service quality. The results of this study are similar [23]. Then this study finds that tourists' image of Lukang also has a positive impact on their behavioral intention, so hypothesis 2 is also supported. The re- 
sults of this study are similar to those of Jiang, Li and Wu (2013) who took the old Xinhua Street as the research object. It shows that the stronger the tourists' cognition and emotion about the tourist destination, the easier it is to promote the tourists' intention to revisit and recommend. It is also similar to relevant research findings [24]. For example, Ho (2018) found that "destination image" has a significant effect on "behavioral intention", indicating that tourists have a correlation between "destination image" and "behavioral intention" of Danshui old street, and the tourists visit willingness have a correlation between destination image and behavioral intention [1].

Then, this study finds that tourists' perceived service quality has a positive impact on their behavioral intention during their stay in Lukang, so hypothesis 3 is also supported. This shows that in the process of traveling in Lukang, tourists will have an important impact on the quality of the preservation of historical relics, the service of scenic spots, the traffic conditions, the service of scenic spots, the catering service, the environmental cleaning, the traffic, the snacks and the public facilities. This will affect the willingness to come to Lukang town to engage in tourism activities in the future, as well as the willingness to recommend relatives and friends. Compared with the previous research [17] [18] [19] [20], the result is the same, that is, the service quality of the destination has an important effect on tourists' behavior intention. Finally, we find that service quality plays a mediating role between image and behavior intention. Although it is found that image has a direct impact on tourists' intention to revisit Lukang and recommend local places, it has a greater impact through the service quality of destination. On the whole, tourists' behavior intention of revisiting Lukang and recommending local places still plays a more important intermediary role in the service quality of local experience.

\subsection{Conclusion}

Based on the above discussion, this study has the following conclusions: 1) Tourists' im ages of Lukang town include diverse folk activities, well-known cultural relics, well-known snacks, well-known handicrafts and Mazu reputation. These images will have an impact on whether tourists feel the same service quality as the image when they visit Lukang. In addition, it also has a positive effect on future travel behavior intention; 2) The service quality experienced by tourists in Lugang, including catering service, environmental cleaning, scenic spot service, snacks and specialties, and residents' friendliness, has a positive effect on their future travel behavior intention; 3) This study also finds that tourists' image of Lukang town also has a mediating effect on tourism behavior intention from their feelings of service quality.

\subsection{Suggestion}

The results of this study show that tourists' perception of the diversified folk activities, well-known cultural relics, special snacks, well-known handicrafts and Mazu reputation of Lugang Town, and the service quality after traveling in Lu- 
gang town will affect tourists' intention to visit Lugang again in the future and recommend their relatives and friends to visit Lugang. So for the local government, the tourism promotion department, and the tourism industry. The first task is to maintain the protection of scenic spots and cultural ease, to maintain the environment clean and clear traffic parking and guidance. The abovementioned approach is also the focus of local tourism marketing so that tourists can have a good image of Lugang when receiving these messages. In addition, all kinds of goods and souvenirs sold, as well as the reasonable price of the restaurant, so that tourists can get a good reputation before visiting, and produce a good image. In the local tourism, the service quality is consistent with the previous image, so that tourists can travel again, and can recommend relatives and friends to visit Lugang. As the friendly attitude of local residents towards the visitors is also very important, Lukang town government and tourism promotion units have a close relationship. When promoting tourism in small towns, it is also necessary to publicize the importance of promoting tourism to residents and ask them to support the development of tourism.

\section{Conflicts of Interest}

The authors declare no conflicts of interest regarding the publication of this paper.

\section{References}

[1] Ho, Y.-F. (2018) A Study of the Relationship among Tourist Destination Image, Satisfaction and Behavioral Intention for Tamsui Old Street in New Taipei City, Taiwan. Unpublished Master Thesis, Aletheia University, New Taipei City.

[2] Wu, P.-H. (2017) A Study on Relationships among Destination Image, Tourism Experience and Behavioral Intentions-An Example of Lukang Township. Unpublished Master Thesis, National Yunlin University of Science and Technology, Yunlin County.

[3] Crompton, J.L. (1979) An Assessment of the Image of Mexico as a Vacation Destination and the Influence of Geographical Location upon that Image. Journal of Travel Research, 17, 18-23. https://doi.org/10.1177/004728757901700404

[4] Bigné, J.E., Sánchez, M.I. and Sánchez, J. (2001) Tourism Image, Evaluation Variables and after Purchase Behavior: Inter-Relationship. Tourism Management, 22, 607-616. https://doi.org/10.1016/S0261-5177(01)00035-8

[5] Lin, Y.-J. (2017) A Study on Tourism Attraction, Service Quality, Facilities, Destination Image, Satisfaction, and Willingness to Revisit in Beimen Visitor Center, Southwest Coast National Scenic Area. Unpublished Master Thesis, Aletheia University, New Taipei City.

[6] Baker, D.A. and Crompton, J.L. (2000) Quality, Satisfaction and Behavioral Intentions. Annals of Tourism Research, 27, 785-804. https://doi.org/10.1016/S0160-7383(99)00108-5

[7] Beerli, A. and Martín, J.D. (2004) Factors Influencing Destination Image. Annals of Tourism Research, 31, 657-681. https://doi.org/10.1016/j.annals.2004.01.010

[8] Echtner, C.M. and Ritchie, J.R.B. (1993) The Measurement of Destination Image: An Empirical Assessment. Journal of Travel Research, 31, 3-13. 
https://doi.org/10.1177/004728759303100402

[9] Leisen, B. (2001) Image Segmentation: The Case of a Tourism Destination, Journal of Services Marketing, 15, 49-66. https://doi.org/10.1108/08876040110381517

[10] Binh, U.C. (2020) A Study of Taiwan Tourism Image, Service Quality and Satisfaction for Vietnamese Tourists. Unpublished Master Thesis, National Kaohsiung University of Science and Technology, Kaohsiung City.

[11] Lin, Y.-F. (2020) A Study on the Relationship among Tourism Image, Tourism Experience and Behavioral Intentions: An Example of Southern Branch of the National Palace Museum. Unpublished Master Thesis, National Yunlin University of Science and Technology, Yunlin County.

[12] Parasuramen, A., Zeithaml, V.A. and Berry, L.L. (1985) A Conceptual Model of Service Quality and Its Implications for Future Research. Journal of Marketing, 49, 41-50. https://doi.org/10.1177/002224298504900403

[13] Fick, G.R. and Ritchie, J.R.B. (1991) Measuring Service Quality in the Travel and Tourism Industry. Journal of Travel Research, 30, 2-9. https://doi.org/10.1177/004728759103000201

[14] Mudner (2020) A Study of Tourist Attraction, Service Quality, and Customer Satisfaction for Russian Group Tourists in Taiwan. Unpublished Master Thesis, Fu Jen Catholic University, New Taipei City.

[15] Hong, S.-Y. (2019) Study on Travel Resources, Service Quality and Tourist Guides' Willingness of Recommendation in Green Island. Unpublished Master Thesis, Far East University, Tainan City.

[16] Chen, C.H. and Tsai, D.C. (2007) How Destination Image and Evaluative Factors Affect Behavioral Intentions? Tourism Management, 28, 1115-1122.

https://doi.org/10.1016/j.tourman.2006.07.007

[17] Chang, H.-M. and Lin, C.-H. (2020) Island Tourism: Participation Behavior of Tourists. Social Behavior and Personality: An International Journal, 48, e8597. https://doi.org/10.2224/sbp.8597

[18] Chang, H.-M., Lin, C.-H. and Huang, Y.-C. (2020) A Study of Behavioral Model on Mazuism Religious Tourism in Taiwan-An Example of Dajia Jenn Lann Temple. International Journal of Religious Tourism and Pilgrimage, 8, 47-59.

[19] Ou, J.-P. (2018) A Study on the Relationship among Tourism Imagery, Satisfaction, and Revisit Intentions in Japanese Tourism. Unpublished Master Thesis, National Penghu University of Science and Technology, Penghu County.

[20] Chang Liao, L.-C. (2010) A Study of Tourist on Travel Images, Qualities, Perceived Value, and Revisiting Willingness in Lukang. Journal of Leisure and Recreation Industry Management, 3, 62-80.

[21] Nunnally, J.C. and Bernstein, I.H. (1994) Psychometric Theory. 3rd Edition, McGraw-Hill, New York.

[22] Hair, J.F., Black, W.C., Babin, B.J. and Anderson, R.E. (2010) Multivariate Data Analysis. 7th Edition, Prentice Hall, Englewood Cliffs.

[23] Chen, Y.-C. (2019) The Relationship among Destination Image, Service Quality, Brand Identity, Community Identity, Satisfaction and Intention-A Case Study of Police Villa Resort in Guanziling, Tainan. Unpublished Master Thesis, Tainan.

[24] Jiang, Y.-R., Li, W. and Wu, L.-G. (2013) A Study on the Relationship between Tourist Image, Tourism Experience and Behavior Intention, Taking Xinhua Old Street as an Example. Journal of Leisure Tourism and Sports Health, 3, 151-173. (In Chinese). 